\title{
Newly synthesized podophyllotoxin derivative, LJ12, induces apoptosis and mitotic catastrophe in non-small cell lung cancer cells in vitro
}

\author{
LING HUI ${ }^{1,2}$, CHUNYAN SANG ${ }^{1,2}$, DONGHONG WANG ${ }^{1,2}$, XIAOHUI WANG $^{1,2}$, \\ MEILIANG WANG $^{1,2}$, QINGHUA JIA ${ }^{1,2}$, MINGREN MA ${ }^{1,2}$ and SHIWU CHEN ${ }^{3}$ \\ ${ }^{1}$ Experimental Center of Medicine; ${ }^{2}$ Key Laboratory for Stem Cell and Gene Drug Study of the Gansu Province, \\ General Hospital of Lanzhou Military Area Command, Lanzhou, Gansu 730050; \\ ${ }^{3}$ School of Pharmacy, Lanzhou University, Lanzhou, Gansu 730000, P.R. China
}

Received January 6, 2015; Accepted October 14, 2015

DOI: $10.3892 / \mathrm{mmr} .2015 .4561$

\begin{abstract}
Deoxypodophyllotoxin (DPT), an active compound isolated from a number of herbs and used in traditional medicine, has been reported to exhibit promising anti-tumor activity. A newly synthesized derivative, $\mathrm{N}$-(1-oxyl-4'-demethyl-4-deoxyp odophyllic)-L-methine-4'-piperazine carbamate (LJ12) may have improved antitumor activity and fewer side effects. The present study assessed the effect of LJ12 on cell viability, apoptosis, cell cycle distribution and mitotic catastrophe in A549 human lung cancer cells in vitro. The molecular mechanisms underlying the antitumor activity of LJ12 were also examined. The results demonstrated that LJ12 reduced A549 cell viability in a time- and dose-dependent manner, with a lower half maximal inhibitory concentration of $\sim 0.1 \mu \mathrm{M}$, compared with another known DPT derivative, etoposide $(10 \mu \mathrm{M})$. Flow cytometric analysis showed that LJ12 induced tumor cell arrest at the G2/M phase of the cell cycle. The present study also observed an expected concomitant decrease in the
\end{abstract}

Correspondence to: Professor Ling Hui, Experimental Center of Medicine, General Hospital of Lanzhou Military Area Command, 333 Binhenan Road, Lanzhou, Gansu 730050, P.R. China

E-mail: zyhuil@hotmail.com

Professor Shiwu Chen, School of Pharmacy, Lanzhou University, 199 Donggang West Road, Lanzhou, Gansu 730000, P.R. China E-mail: chenshw@lzu.edu.cn

Abbreviations: DAPI, 4',6-diamidino-2-phenylindole; DMSO, dimethyl sulfoxide; DPT, deoxypodophyllotoxin; ECL, enhanced chemiluminescence; PBS, phosphate-buffered saline; VP16, etoposide; $\mathrm{IC}_{50}$, half maximal inhibitory concentration; PPT, podophyllotoxin; TBST, Tris-buffered saline-Tween 2; SDS-PAGE, sodium dodecyl sulfate-polyacrylamide gel electrophoresis

Key words: apoptosis, cell cycle arrest, deoxypodophyllotoxin, mitotic catastrophe, cell proliferation numbers of cells cells in the G0/G1 and S phases. LJ12 was found to upregulate the protein expression levels of $\mathrm{Cdc} 2$ and Cyclin B1. Furthermore, LJ12 induced tumor cell apoptosis and the protein expression of B cell lymphoma-2-associated $\mathrm{X}$ protein, caspase- 3 and $\mathrm{p} 53$. The present study also observed the formation of giant, multinucleated cells, indicating that LJ12 induced mitotic catastrophe in the tumor cells. These results indicated that $\mathrm{LJ} 12$ has anti-non-small cell lung cancer activity in vitro. Further investigations aim to develop LJ12 as a therapeutic agent for the treatment of lung cancer.

\section{Introduction}

Lung cancer is one of the leading causes of cancer-associated mortality worldwide (1). Non-small cell lung cancer (NSCLC) constitutes up to $85 \%$ of all lung cancer cases (2) and is frequently diagnosed at the advanced stages of disease; thus, curable surgical intervention is not usually an option. Additionally, NSCLC is resistant to chemotherapy $(3,4)$ and radiation treatment, resulting in a poor overall 5-year survival rate for patients with NSCLC of $<15 \%$ (2). Cisplatin is the most widely used chemotherapeutic agent for NSCLC treatment; however, the effect of cisplatin on NSCLC has several limitations, including insensitivity in certain patients and high levels of toxicity (5). Thus, there is a critical requirement for the improved early diagnosis of lung cancer and development of novel therapies and strategies for the treatment of lung cancer. The development of anticancer therapeutic agents from natural products is an area of considerable interest and importance (5).

Podophyllotoxin (PPT) is isolated from the roots and rhizomes of Podophyllum species, including Podophyllum hexandrum and Podophyllum peltatum. The compound appears to have useful antimitotic/cytotoxic activities and offers potential as an agent for antitumor therapy. Semi-synthetic PPT compounds, including etoposide (VP16), etopophos and teniposide, have been developed and are currently being used clinically to treat lung cancer and other neoplasms, including refractory testicular tumors, lymphoma and nonlymphomatic leukemia $(6,7)$. However, due to cancer cell drug resistance and the side effects associated with PPT and associated 
compounds, the identification of more potent, but less toxic, anticancer analogues of PPT has become an intense area of investigation (8). Deoxypodophyllotoxin (DPT) is a potent antitumor and anti-inflammatory agent in vitro, which has a close structural association with PPT $(9,10)$. In our previous study, nine novel derivatives of DPT were synthesized (11). The results identified one novel derivative, incorporating L-amino acid, which demonstrated superior antitumor activity, compared with VP16 in various cancer cell lines, including the NSCLC A549 cell line. Therefore, the present study investigated the anticancer effects and molecular activities of this derivative, N-(1-oxyl-4'-d emethyl-4-deoxypodophyllic)-L -me thine-4'-piperazine carbamate (LJ12; Fig.1), in the human NSCLC A549 cell line in vitro.

\section{Materials and methods}

Cell lines and culture. Human A549 NSCLC, HepG2 hepatocellular carcinoma, and Hela and SiHa cervical cancer cell lines were obtained from the Center of Experimental Medicine (Lanzhou, China) and maintained in RPMI-1640 medium (Gibco; Thermo Fisher Scientific, Inc., Waltham, MA, USA), supplemented with $10 \%$ newborn calf serum (Hangzhou Sijiqing Biological Engineering Materials Co., Ltd., Hangzhou, China), $100 \mu \mathrm{g} / \mathrm{ml}$ streptomycin and $100 \mathrm{IU} / \mathrm{ml}$ penicillin (Sigma-Aldrich, St. Louis, MO, USA) at $37^{\circ} \mathrm{C}$ in a humidified atmosphere of $5 \% \mathrm{CO}_{2}$.

3-[4,5-Dimethylthiazo l-2-yl]-2,5-diphenyl-tetrazolium bromide (MTT) assay of cell viability. The effect of LJ12, synthesized by the School of Pharmacy of Lanzhou University (Lanzhou, China) on the regulation of cell viability was assayed using MTT (Sigma-Aldrich). The cells were seeded at a density of $5 \times 10^{3}$ cells per well and grown overnight, following which they were treated with $\mathrm{LJ} 12$ at various doses $(0.001-10 \mu \mathrm{M})$ and durations $(12-60 \mathrm{~h})$ at $37^{\circ} \mathrm{C}$ in an atmosphere containing $5 \% \mathrm{CO}_{2}$. LJ12 was synthesized in the laboratory at the School of Pharmacy of Lanzhou University, according to methods described previously (12), and was $8.59 \mathrm{mg} \mathrm{LJ} 12$ was dissolved in dimethyl sulfoxide (DMSO; Sigma-Aldrich) at a concentration of $100 \mathrm{mM}$ as a stock solution. The final DMSO concentration used in the culture medium was below $0.1 \%$ (v/v). Following incubation with the drug, $20 \mu \mathrm{l}$ MTT solution $(5 \mathrm{mg} / \mathrm{ml})$ was added to each well, and the plates were further incubated for $4 \mathrm{~h}$ at $37^{\circ} \mathrm{C}$. Subsequently, $150 \mu \mathrm{l} \mathrm{DMSO}$ was added into each well to dissolve the MTT-converted products, and the optical density of each well was measured at $570 \mathrm{~nm}$ using a microplate reader (Bio-Rad 550; Bio-Rad Laboratories, Inc., Hercules, CA, USA). VP16, obtained from Jiangsu Hengrui Medicine Co., Ltd. (Nanjing, China) was used, at the same concentrations as in the treatment groups, as a positive control. DMSO was used as the vehicle control.

Flow cytometric analysis of cell cycle and apoptosis. The cells were seeded in culture flasks at a density of $2.5 \times 10^{5}$ and treated with LJ12 or VP16 at various concentrations for 12 or $24 \mathrm{~h}$ at $37^{\circ} \mathrm{C}$ in $5 \% \mathrm{CO}_{2}$. Following treatment, the cells were washed with phosphate-buffered saline (PBS), fixed in ice-cold $70 \%$ ethanol at $4^{\circ} \mathrm{C}$ overnight and stained with a propidium iodide (PI; Sigma-Aldrich) solution $(80 \mu \mathrm{g} / \mathrm{ml})$ containing
Triton X-100 (0.1\%; v/v; Sigma-Aldrich) and RNase A (100 $\mu \mathrm{g} / \mathrm{ml}$; Sigma-Aldrich) in PBS. Following staining, the DNA content was analyzed using a BD FACSCalibur flow cytometer (BD Biosciences, Franklin Lakes, NJ, USA) and CellQuest Pro software (BD Biosciences).

For the assessment of cell apoptosis, the LJ12 or VP16 treated cells were subjected to Annexin V-PI staining using an Annexin V-fluorescein isothiocyanate/PI double staining apoptosis detection kit (Nanjing Jiancheng Bioengineering Institute, Nanjing, China). Briefly, $2 \times 10^{5}$ A549 cells were treated with LJ12 $(0.05 \mu \mathrm{M})$ for 6,12 and $24 \mathrm{~h}$, harvested, washed twice with PBS and resuspended in $500 \mu 1$ 1X Hepes binding buffer (Nanjing Jiancheng Bioengineering Institute). Subsequently, $5 \mu \mathrm{l}$ Annexin $\mathrm{V}$ and $5 \mu \mathrm{l}$ PI were added to the cell solution, mixed and incubated at the room temperature in the dark for $5 \mathrm{~min}$, followed by analysis using the BD FACSCalibur flow cytometer and CellQuest Pro 4.0 software (BD Biosciences, Franklin Lakes, NJ, USA).

Hoechst 33258 staining and evaluation of cell morphology. The apoptotic nuclei of the tumor cells were visualized using Hoechst $33258(10 \mu \mathrm{g} / \mathrm{ml}$, Sigma-Aldrich) staining. The A549 cells $\left(2.5 \times 10^{5} /\right.$ well $)$ were grown on glass slides to $\sim 70-80 \%$ confluency, and were then treated with $0.5 \mu \mathrm{M} \mathrm{LJ} 12$ or VP16 for $24 \mathrm{~h}$ at $37^{\circ} \mathrm{C}$ in an atmosphere containing $5 \% \mathrm{CO}_{2}$. Following treatment, the cells were fixed, washed twice with PBS and stained with Hoechst 33258 staining solution, according to the manufacturer's protocol (Beyotime Institute of Biotechnology, Jiangsu, China). Chromosomal condensation and morphological changes were observed and quantified using an Olympus BX61 fluorescence microscope (Olympus Corporation, Tokyo, Japan).

Immunofluorescence. The A549 cells (2.5x10 $/$ well) were plated onto coverslips and then treated with or without $0.5 \mu \mathrm{M} \mathrm{VP16}$ or $\mathrm{LJ} 12$ for $24 \mathrm{~h}$ at $37^{\circ} \mathrm{C}$ in an atmosphere containing $5 \% \mathrm{CO}_{2}$. Following treatment, the cells were fixed with $4 \%$ paraformaldehyde (Tianjin Tuo Ou Li Yuan Chemical Co., Ltd., Tianjin, China) in PBS for $4 \mathrm{~h}$ at room temperature and permeabilized in $0.1 \%$ Triton X-100 in PBS for $30 \mathrm{~min}$ at room temperature. The cells were then incubated with primary mouse anti-human $\alpha$-tubulin monoclonal antibody (1:500; cat. no. sc-5286; Santa Cruz Biotechnology, Inc., Santa Cruz, CA, USA) for $90 \mathrm{~min}$ at $37^{\circ}$, followed by incubation with goat anti-mouse fluorescein isothiocyanate-labeled IgG (1:100; cat. no. ZF-0312; Beijing Zhongshan Golden Bridge Biotechnology Co., Ltd., Beijin, China) for $30 \mathrm{~min}$ at $37^{\circ} \mathrm{C}$. The cells were further stained for 5 min with $300 \mathrm{nM}$ 4,6-dianidino-2-phenylindole (DAPI; Sigma-Aldrich). Images of the stained cells were captured and data were quantified using an Olympus BX61 fluorescence microscope (Olympus Corporation).

Protein extraction and western blot analysis. The A549 cells were treated, as described above, harvested and lysed with cell lysis buffer containing $1 \mathrm{mM}$ Tris- $\mathrm{HCl}(\mathrm{pH} 7.5), 0.1 \mathrm{mM}$ $\mathrm{Na}_{2}$ EDTA, $15 \mathrm{mM} \mathrm{NaCl}, 0.1 \mathrm{mM}$ EGTA, $0.25 \mathrm{mM}$ sodium pyrophosphate, $0.1 \%$ Triton $\mathrm{X}-100,0.1 \mathrm{mM} \mathrm{Na}_{3} \mathrm{VO}_{4}, 0.1 \mathrm{mM}$ $\beta$-glycerophosphate, $0.2 \mathrm{mM}$ phenymethylsul-fonyl fluoride and $0.1 \mu \mathrm{g} / \mathrm{ml}$ leupeptin (all from Sigma-Aldrich). The lysates were centrifuged at $12,000 \mathrm{xg}$ for $15 \mathrm{~min}$ at $4^{\circ} \mathrm{C}$ and the protein 


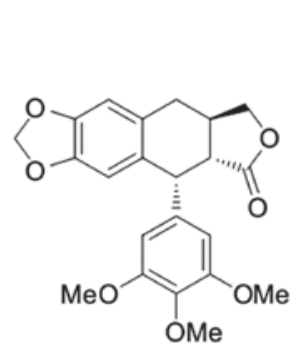

DPT

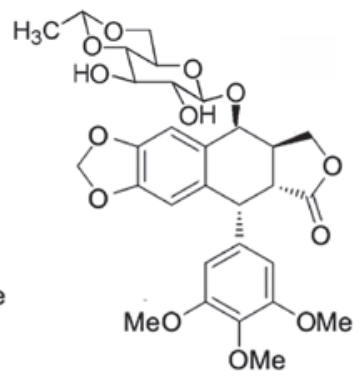

VP16

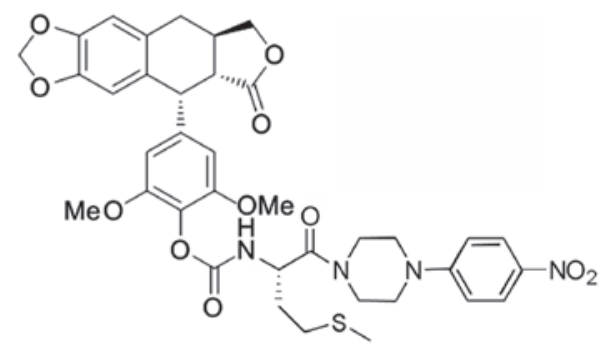

LJ12

Figure 1. Chemical structures of DPT and the DPT derivatives, LJ12 and VP16. DPT, deoxypodophyllotoxin; LJ12, N-(1-oxyl-4'-demethyl-4-deoxypo dophyllic)-L-methine-4'-piperazine carbamate; VP16, etoposide.

concentration in the supernatant was determined using the Bradford method. Equal quantities of protein (30-40 $\mu \mathrm{g})$ were separated via $12 \%$ sodium dodecyl sulfate-polyacrylamide gel electrophoresis and electrotransferred onto polyvinylidene fluoride membranes (EMD Millipore, Billerica, MA, USA). For western blot analysis, the membranes were blocked in $5 \%$ dried skimmed milk in Tris-buffered saline-Tween 20 for $1 \mathrm{~h}$, followed by incubation overnight at $4^{\circ} \mathrm{C}$ with the indicated primary antibody. The membranes were then incubated at $37^{\circ} \mathrm{C}$ for $2 \mathrm{~h}$ with horseradish-peroxidase-conjugated secondary antibodies (1:100) and the protein band was developed using an enhanced chemiluminescence detection system (UVP Inc., Upland, CA, USA). $\beta$-actin was used as a loading control. The primary and secondary antibodies used were as follows: Goat anti-human polyclonal p-Cdc2 (p34; 1:500; cat. no. sc-7989-R), mouse anti-human monoclonal caspase 3 (1:500; cat. no. sc-271028), mouse anti-human monoclonal p53 (1:2,000; cat. no. sc-126), rabbit anti-human polyclonal B cell lymphoma-2 (Bcl-2)-associated X protein (Bax; 1:1,000; cat. no. sc-493), rabbit anti-human polyclonal Bcl-2 (1:1,000; cat. no. sc-492) and goat anti-human polyclonal $\beta$-actin (1:1,000; cat. no. sc-1616) were purchased from Santa Cruz Biotechnology, Inc. Mouse anti-human monoclonal cyclin B (1:500; cat. no. 647901), and mouse anti-human polyclonal cdc2 (p34) were purchased from Biolegend (BioLegend Inc. San Diego. CA, USA). Horse anti-mouse IgG-AP (cat. no. ZB-2310), goat anti-rabbit IgG-AP (cat. no. ZB-2308) and rabbit anti-goat IgG-AP (cat. no. ZB-2311) (all 1:5,000) were from purchased from Beijing Zhongshan Golden Bridge Biotechnology Co., Ltd.

Statistical analysis. All statistical analyses were performed using SPSS software version 17 (SPSS, Inc., Chicago, IL, USA). Statistical significance was determined at the $95 \%$ confidence interval using Student's t-test. All data are expressed as the mean \pm standard deviation, which was calculated automatically using SPSS. $\mathrm{P}<0.05$ was considered to indicate a statistically significant value.

\section{Results}

Cytotoxic effects of LJ12 on cancer cell lines in vitro. With the aim of identifying more potent antitumor agents, the present study synthesized LJ12 in the laboratory and investigated its effects on the viability of A549, HepG2 and Hela cancer cells. The structure of LJ12, and how it compares with other derivatives, is shown in Fig. 1. In the present study, the cells were treated with various concentrations of LJ12 for varying lengths of time (Fig. 2). Subsequent MTT assays showed that LJ12 reduced the viability of the A549, HepG2 and Hela cells in a dose- and time-dependent manner (Fig. 2A). The half maximal inhibitory concentration $\left(\mathrm{IC}_{50}\right)$ values of $\mathrm{LJ} 12$, determined following $48 \mathrm{~h}$ treatment, were $0.183,0.21$ and $0.191 \mathrm{M}$ for the A549, HepG2 and Hela cells, respectively. The $\mathrm{IC}_{50}$ values determined for LJ12 were markedly lower than the observed corresponding $\mathrm{IC}_{50}$ values of VP16 (14.8, 28.4 and $50.6 \mu \mathrm{M}$ for the A549, HepG2 and Hela cells, respectively). In addition, it was found that the cells treated with LJ12 exhibited morphological changes, which were typical of tumor cell apoptosis (Fig. 2B), including cell shrinkage and condensed chromatin. These findings suggested that LJ12 opposed the proliferation of A549, HepG2 and Hela cells. The present study focussed on A549 cells for the subsequent experiments, as VP16, which is similar to LJL2 structurally, is currently used as a first-line treatment in small cell lung cancer (13).

LJ12 treatment induces A549 cell cycle arrest. In the initial cytotoxicity assessment, a significant enlargement in the size of certain cells was observed in the LJ12-treated A549 cells. To evaluate whether LJ12 affected mitosis, the present study examined the effect of LJ12 treatment on the cell cycle distribution of the A549 cells. The percentage of A549 cells in the G1 phase was substantially lower following treatment with LJ12, compared with the percentage of control cells in the G1 phase (Fig. 3A-C). This decrease was reflected in an increase in the population of cells in the $\mathrm{G} 2 / \mathrm{M}$ phase, with $\sim 77.3 \%$ of the cells in the $\mathrm{G} 2 / \mathrm{M}$ phase following $12 \mathrm{~h}$ treatment with $0.05 \mu \mathrm{M}$ LJ12 (Fig. 3B). In the untreated control cells, the G2/M phase population was $\sim 11.5 \%$. Furthermore, the G2/M phase distribution of cells treated for $12 \mathrm{~h}$ with $0.1,0.2$ and $0.5 \mu \mathrm{M} \mathrm{LJ} 12$ (92.0-93.7\%) were 3.4- to 4-fold higher, compared with the $\mathrm{G} 2 / \mathrm{M}$ phase distribution of cells treated for $24 \mathrm{~h}$ with $0.5 \mu \mathrm{M}$ VP16 (23.0\%). However, the G2/M phase distribution of the VP16-treated cells was significantly increased, compared with that of the control cells (10.1\%). In additionally, even the cells treated with a $2.0 \mu \mathrm{M}$ dose of VP16 for $24 \mathrm{~h}$ had significantly fewer cells in the G2/M phase, compared with the cells treated for $12 \mathrm{~h}$ with just $0.05 \mu \mathrm{M} \mathrm{LJ12}$ (Fig. 3C).

LJ12 induction of tumor cell apoptosis. The Hoechst 33258 staining performed in the present study revealed that LJ12 
A

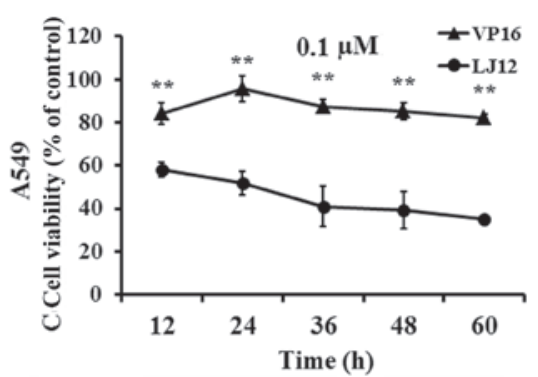

B

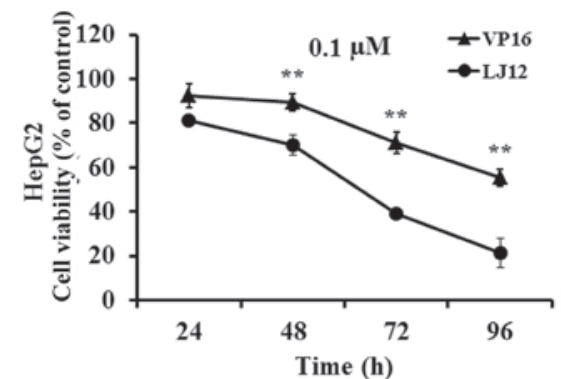

C

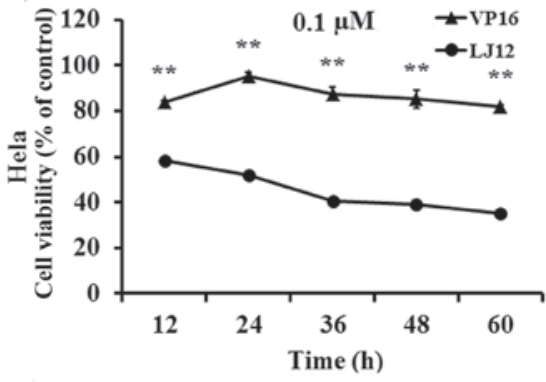

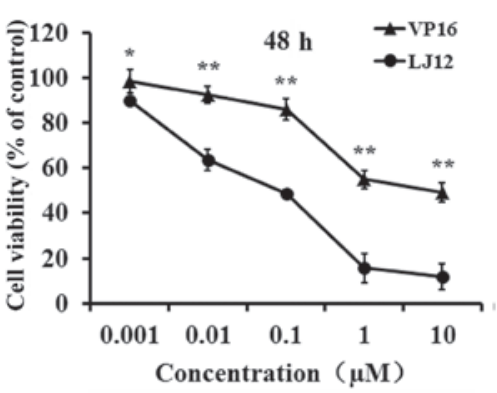
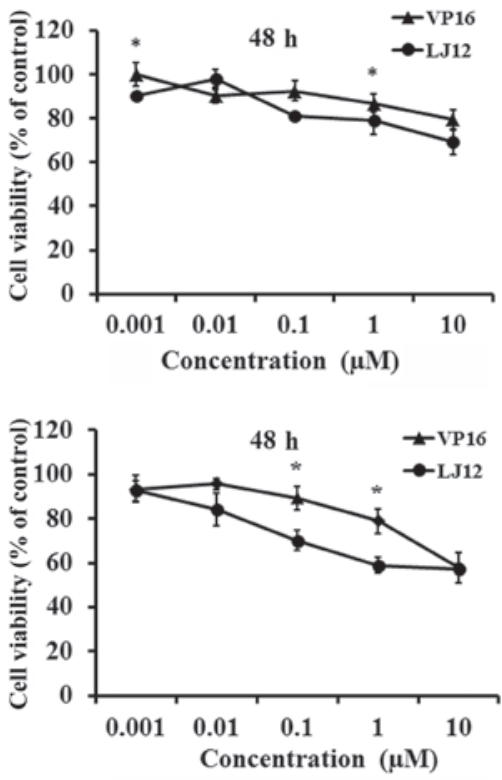

D

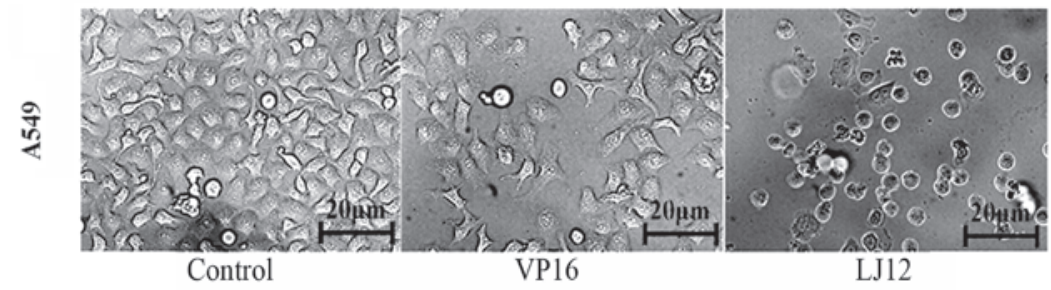

Figure 2. Antiproliferative effects of LJ12 and VP16 in different cancer cells. (A) A549, (B) HepG2 and (C) Hela cells were grown and treated with different concentrations of VP16 or LJ12 (0.001-10 $\mu \mathrm{M})$ for varying periods of time (12-60 h). Cell viability was assayed using a 3-[4,5-dimethylthiazo 1-2-yl]-2,5-diphenyl-tetrazolium bromide assay. (D) Morphological analysis of A549 cells following $24 \mathrm{~h}$ treatment with $0.05 \mu \mathrm{M}$ VP-16 or $0.05 \mu \mathrm{M}$ LJ12 (magnification, x200). A549 cells treated with LJ12 displayed typical morphological features of apoptosis, including cell shrinkage and condensed chromatin. Values are expressed as the mean \pm standard error of the mean from at least four independent experiments $(\mathrm{n}=4)$. ${ }^{*} \mathrm{P}<0.05$, vs. VP16, ${ }^{* *} \mathrm{P}<0.01$, vs. VP16. LJ12, N-(1-oxyl-4'-demethyl-4-deoxypo dophyllic)-L-methine-4'-piperazine carbamate; VP16, etoposide.

treatment evoked typical apoptotic features in cells, including nuclear condensation and fragmentation, cell shrinkage and detachment (Fig. 4A). These observations were confirmed using a flow cytometric Annexin V-PI assay (Fig. 4B). LJ12 induced apoptosis at a dose of $0.05 \mu \mathrm{M}$. The rate of early apoptosis in the LJ12-treated cells was significantly increased, after 12 and $24 \mathrm{~h}$, compared with the control cells $(20.47$ and $19.15 \%$, vs. $0.06 \%$, respectively). The rate of apoptosis following treatment with $0.05 \mu \mathrm{M} \mathrm{LJ} 12$ for $24 \mathrm{~h}(19.15 \%)$ was also elevated, compared with the rate of apoptosis observed following treatment with $0.5 \mu \mathrm{M}$ VP16 for $24 \mathrm{~h}$ (13.99\%; Fig. 4B).

LJ12 treatment and the regulation of microtubule structure and mitotic catastrophe. Mitotic catastrophe is a type of cell death that occurs during abnormal mitosis. It usually leads to the formation of large multiple nuclear cells with de-condensed chromatin (14). To assess the morphology of tumor cells following LJ12 treatment, the present study used indirect immunofluorescence with anti-tubulin antibody staining of microtubules and DAPI staining of nuclei. The results revealed elongated, thin bundles of microtubules distributed throughout the cytoplasm in the untreated control cells and in the VP16-treated cells (Fig. 5A). By contrast, following $24 \mathrm{~h} \mathrm{LJ12}$ treatment, the cells became round and shrinkage was observed, but they contained short, dense microtubule networks. LJ12 treatment also induced multipolar cell division and cells that containing multiple nuclei were observed (Fig. 5B). Cells with double nuclei and giant multinuclear cells are hallmarks of mitotic catastrophe and were frequently observed in the LJ12-treated A549 cells (Fig. 5B). The numbers of giant multinuclear cells were 21.4, 4.2 and 2.4 in the LJ12-treated cells, VP16-treated cells and control cells, respectively, with a significant increase in the LJ12-treated cells. 
A
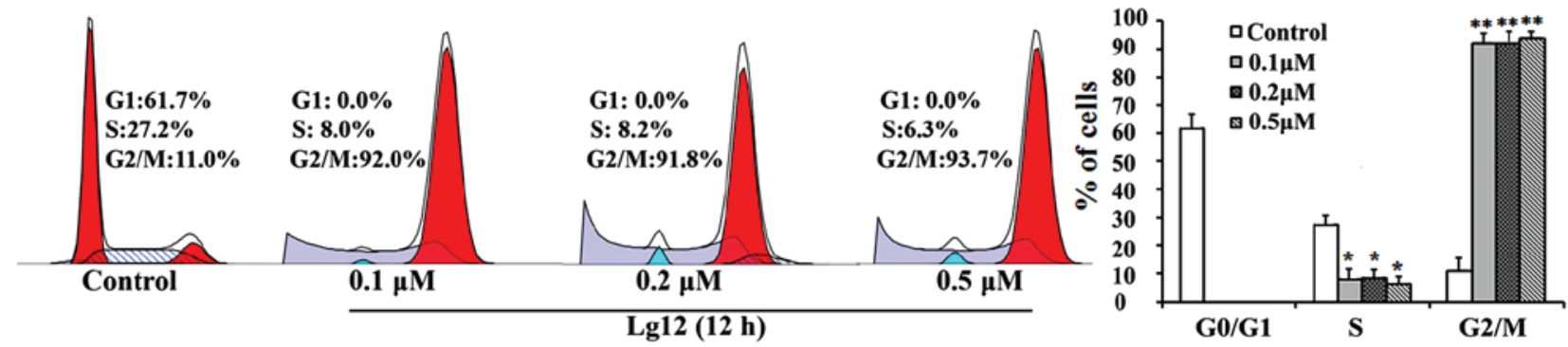

B
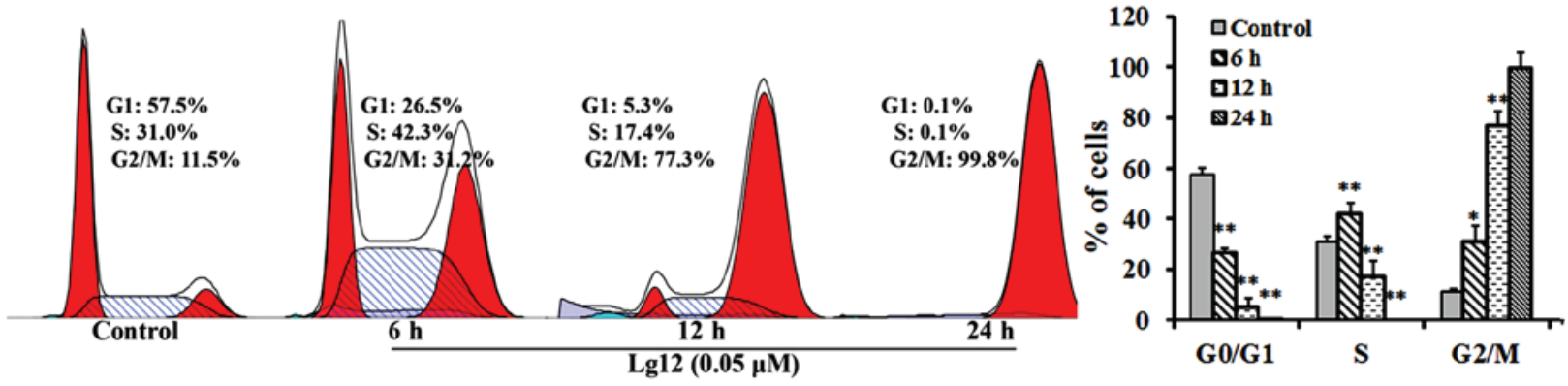

C
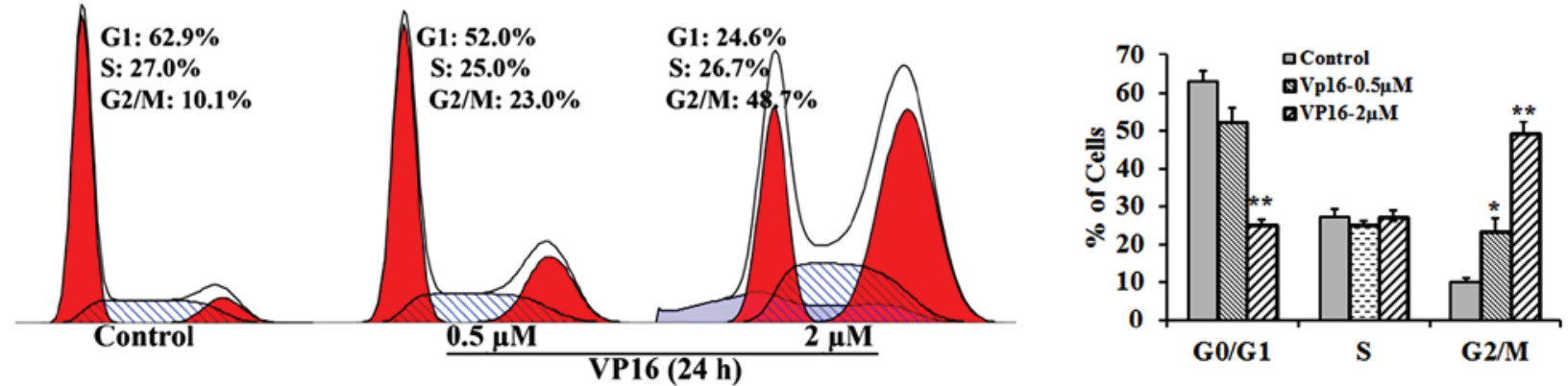

Figure 3. Effects of LJ12 and VP16 treatments on A549 cell cycle distribution. The response of cells treated with (A) $0.1,0.2$ and $0.5 \mu \mathrm{M} \mathrm{LJ} 12$ for $24 \mathrm{~h}$, the response of cells treated with (B) $0.05 \mu \mathrm{M} \mathrm{LJ} 12$ for $0,6,12$ and $24 \mathrm{~h}$ and the response of cells to (C) VP16 (0.5 and $2 \mu \mathrm{M})$ for $24 \mathrm{~h}$ were examined. Following treatment, the cells were subjected to a flow cytometric analysis for detection of the cell cycle distribution. Representative cell cycle distribution figures are shown. The percentages of the cell populations in the different phases of the cell cycle (G0/G1, S and G2/M) were analyzed. ${ }^{*} \mathrm{P}<0.05$ and ${ }^{* *} \mathrm{P}<0.05$, vs. the control. LJ12, N-(1-oxyl-4'-demethyl-4-deoxypo dophyllic)-L-methine-4'-piperazine carbamate; VP16, etoposide.

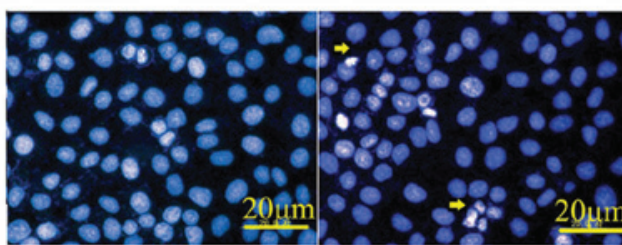

Control
VP16

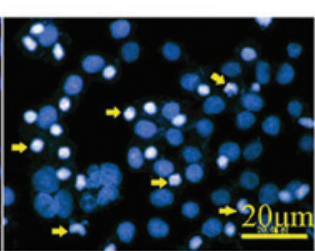

LJ12

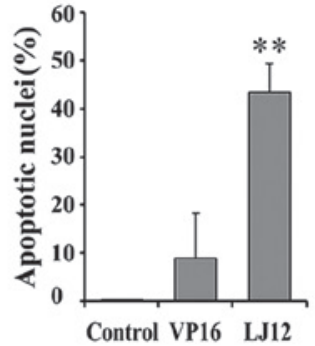

B

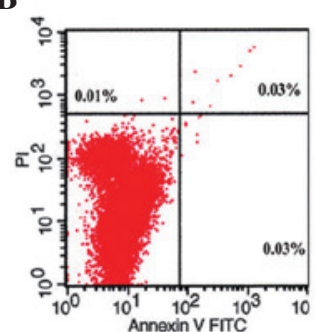

Control

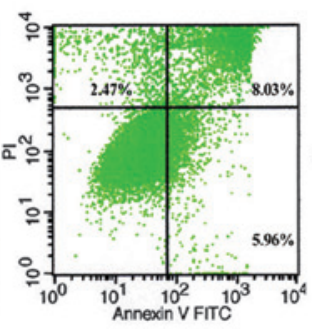

VP16-24 h

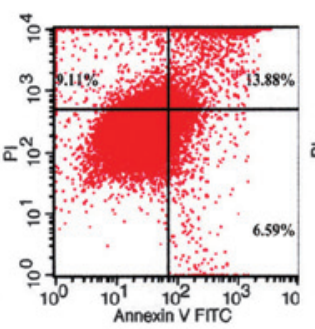

LJ12-12 h

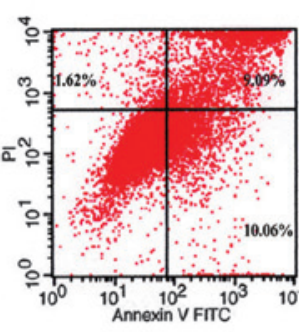

LJ12-24 h

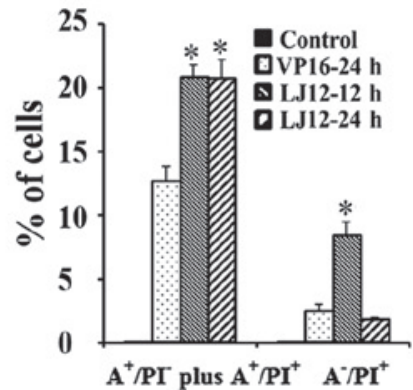

Figure 4. LJ12 induces A549 cell apoptosis. (A) Hoechst staining of A549 cells. The cells were treated with or without $0.5 \mu \mathrm{M}$ LJ12 or VP16 for 48 h, and were observed using a phase contrast microscope. Fragmented nuclei and apoptotic bodies are indicated by yellow arrows. ( $\mathrm{n}=15$; ${ }^{* *} \mathrm{P}<0.001$, vs control and $\left.\mathrm{VP} 16\right)$. (B) Apoptosis of the A549 cells following treatment with $0.05 \mu \mathrm{M} \mathrm{LJ} 12$ for 12-24 h, detected using flow cytometry with an Annexin V/PI apoptosis detection kit. (n=3; 'P<0.05, vs VP16). Error bars represent the mean \pm standard error of the mean. LJ12, N-(1-oxyl-4'-demethyl-4-deoxypo dophyllic)-L-methine-4'-piperazine carbamate; VP16, etoposide; PI, propidium iodide; FITC, fluorescein isothiocyanate. 
A
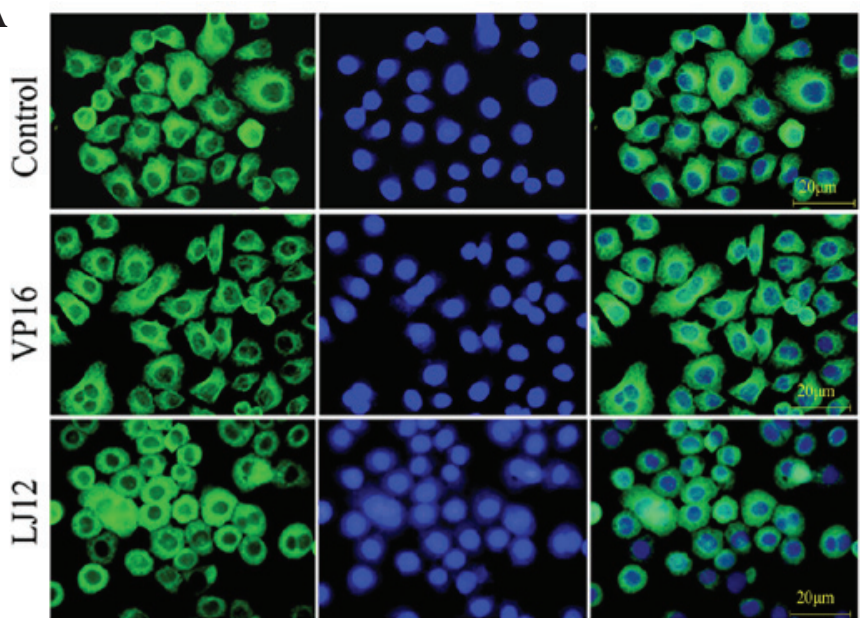

B

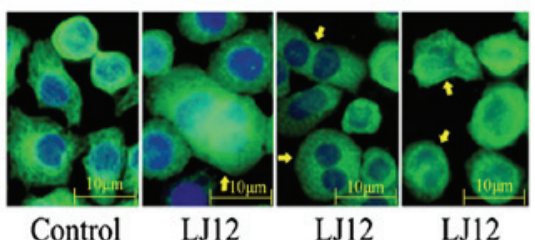

C

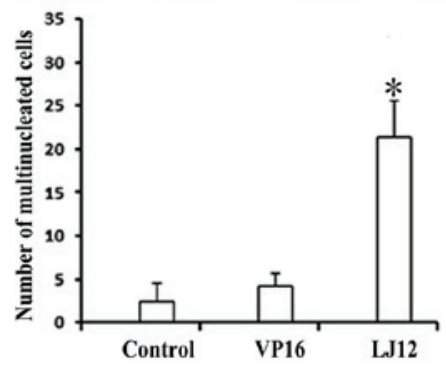

Figure 5. LJ12 effects on microtubule formation and mitotic catastrophe in A549 cells. (A) Immunofluorescence staining of microtubules in the A549 cells. The A549 cells were treated with $0.05 \mu \mathrm{M} \mathrm{LJ} 12$ or VP16 for $24 \mathrm{~h}$. Microtubules were stained with anti- $\alpha$-tubulin antibody and a fluorescein isothiocyanate-conjugated secondary antibody (green). Chromosomal DNA was stained with 4,6-dianidino-2-phenylindole (blue). The morphology of the cells was observed and images were captured using a fluorescence microscope. (B) Immunofluorescence staining of microtubules and cell nuclei. A number of double nuclei cells and giant multinuclear cells (indicated by yellow arrows) were observed in the LJ12-treated A549 cells. (C) Numbers of double nuclei cells and multinuclear cells. ( $\mathrm{n}=15$; " $\mathrm{P}<0.05$, vs. control and VP16). Error bars represent the mean \pm standard error of the mean. LJ12, N-(1-oxyl-4'-demethyl-4-deoxypo dophyllic)-L-methine-4'-piperazine carbamate; VP16, etoposide.

A

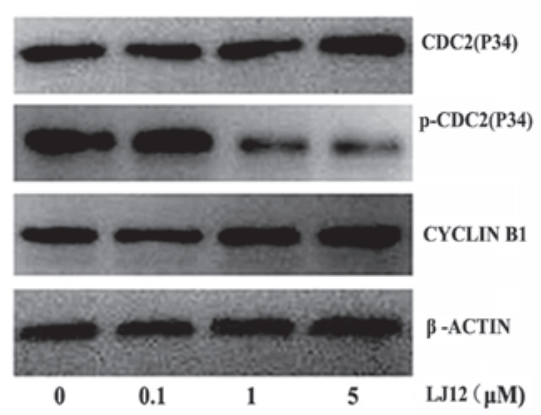

B
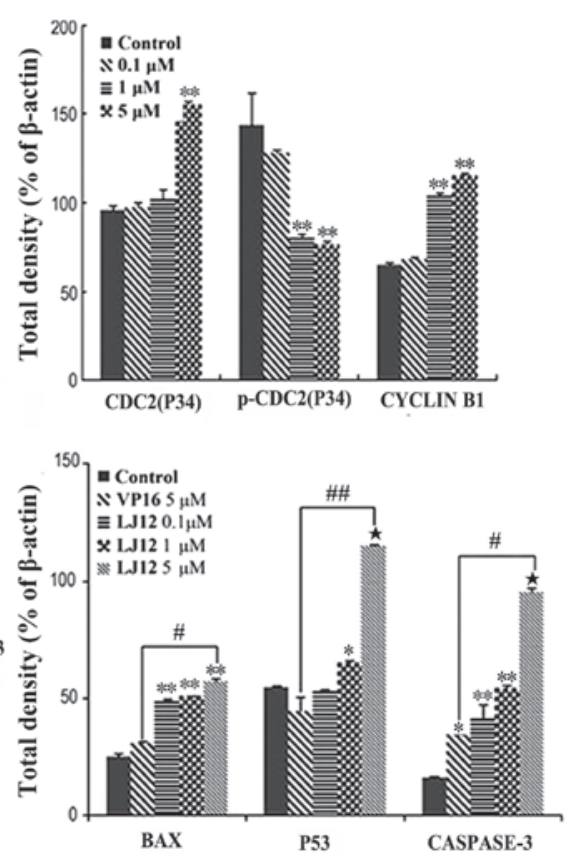

Figure 6. LJ12 regulates gene expression in A549 cells. The A549 cells were treated with 0, 0.1, 1 or $5 \mu \mathrm{M} \mathrm{LJ12}$ for $24 \mathrm{~h}$ and subjected to (A) western blot analyses of apoptosis-associated proteins or (B) cell cycle-associated proteins. The graphs show the quantified data of the corresponding western blot. Data are expressed as the mean \pm standard error of the mean $\left(\mathrm{n}=3 ;{ }^{*} \mathrm{P}<0.05,{ }^{* *} \mathrm{P}<0.01\right.$ and ${ }^{* * *} \mathrm{P}<0.001$, vs control; ${ }^{* \prime} \mathrm{P}<0.01$, vs. VP16 and ${ }^{\# \#} \mathrm{P}<0.001$, vs. VP16). LJ12, $\mathrm{N}$-(1-oxyl-4'-demethyl-4-deoxypo dophyllic)-L-methine-4'-piperazine carbamate; VP16, etoposide. Bax, B cell lymphoma-2-associated X protein; p-cdc2, phosphorylated-cyclin-dependent kinase 2.

LJ12 treatment and regulation of the expression levels of p53, Bax, caspase-3 and cyclin-dependent kinase 2 $(c d c 2) / c y c l i n$ B1. The present study also assessed the effect of LJ12 treatment on the expression levels of various proteins. The results revealed a marked increase in the protein expression levels of cyclin B1 and cdc2 in the LJ12-treated A549 cells, compared with the control cells. However, the protein expression of $\mathrm{p}$-cdc2 was decreased relative to the control cells (Fig. 6A). Following 0.1-5 $\mu \mathrm{M}$ LJ12 treatment, the expression levels of p53, Bax and caspase 3 were all induced in the A549 cells (Fig. 6B). The effect of LJ12 treatment on the expression of cell-cycle regulator proteins was also dose-dependent.

\section{Discussion}

In the present study, the in vitro antitumor effects of LJ12 in NSCLC cells were examined. The data revealed that LJ12 treatment significantly reduced A549 cell viability, and that 
the antitumor activity of LJ12 was more marked, compared with that of the closely associated VP16. It was observed that LJ12 treatment regulated the expression levels of various genes, including cell cycle and apoptosis-associated genes. The expression profiles of these genes following LJ12 treatment were different from the expression profiles following VP16 treatment. These findings indicated that LJ12 may offer potential as an anti-NSCLC drug. However, in vivo investigations are required prior to this drug being considered for testing in Phase I or II clinical trials.

To evaluate the potential effectiveness of LJ12 as an antitumor therapeutic agent, the present study investigated the time- and dose-dependent regulation of the lung carcinoma A549 cell line by LJ12. The $\mathrm{IC}_{50}$ of LJ12 was $0.1 \mu \mathrm{M}$, which was favorable, compared with the VP16 DPT derivative, $\left(\mathrm{IC}_{50}, 10 \mu \mathrm{M}\right)$. Apoptosis is a type of programmed cell death with common identifiable characteristics, which include membrane blebbing, cell shrinkage, chromosome condensation and specific biochemical changes, including activation of the caspase-cascade (15). The present study demonstrated LJ12 treatment induced $>40 \%$ of the A549 cells to undergo apoptosis, compared with $<10 \%$ in the VP16-treated tumor cells. This lower $\mathrm{IC}_{50}$ value and elevated apoptotic induction indicated that LJ12 may have more marked antitumor activity and lower toxicity, compared with VP16.

Mitotic catastrophe is a type of cell death, which usually occurs during mitosis in response to DNA damage or anti-mitotic agents (16). In addition to inducing tumor cell death via apoptosis, LJ12 treatment also induced mitotic catastrophe, supporting previous evidence that LJ12 may be an ideal antitumor therapeutic agent $(17,18)$. Although several biochemical changes associated with mitotic catastrophe have been found, there remains no specific mitotic catastrophe marker (19). Therefore, the identification of mitotic catastrophe depends on cell morphology. Anticancer agents can induce cytokinesis failure, which results in multinucleation and may lead to cell death (20). Multinuclear cells, premature chromosome condensation, aberrant mitotic figures and the accumulation of affected cells in the G2/M phase are characteristic of mitotic catastrophe (20). In the present study, it was found that LJ12 treatment of the A549 cells induced multinucleate giant cells and cells with double nuclei, indicating that LJ12-induced cell death occurred partially through mitotic catastrophe. It was also demonstrated that the LJ12-treated cells expressed apoptotic and mitotic catastrophe-associated biochemical markers, providing further evidence that LJ12 induces apoptosis and mitotic catastrophe in A549 cells. Certain previous studies have shown that mitotic catastrophe and apoptosis are independent pathways, whereas others indicated that mitotic catastrophe may be a specific type of apoptosis, or a precursor of apoptosis or necrosis $(21,22)$. However, the present study was unable not delineate whether apoptosis induced by LJ12 was an independent event, or whether apoptosis occurred due to LJ12-induced mitotic catastrophe. Therefore, further investigation is required to clarify which LJ12-induced cell death pathway is dominant in A549 cells. However, despite this point of controversy, cell death is always the final result.

The suppression of microtubule dynamics by microtubule-targeting drugs, including vinca alkaloids and taxol, can engage the mitotic spindle checkpoint and suppress cell cycle progression, eventually inducing apoptosis (23). However, the direct inhibition of microtubule dynamics may also disrupt a number of normal cellular processes, including the transportation of intracellular cargo or organelles within cells (24). Substantial effort is being made to identify, design and develop antimitotic agents, which bind indirectly to tubulin and alter microtubule dynamics with minimal toxicity to normal tissues. Tubulin is a basic microtubule component, which is involved in several important cellular processes, including cell division, chromosome segregation and cell shape maintenance (25). Tubulin polymerization is a key mechanism of normal microtubule function. Therefore, agents, which affect tubulin polymerization can induce cell death (26). The induction or inhibition of tubulin polymerization can affect the dynamic instability, proper attachment and movement of chromosomes during the various stages of the mitotic phase, leading to mitotic arrest and cell death (26). Thus, highly proliferative cancer cells can be selectively eliminated by drugs, which affect the dynamics of tubulin polymerization (27). A number of anticancer agents targeting this mechanism have been developed and used to treat human cancer (28). However, further investigation is required to investigate how LJ12 treatment targets tubulin polymerization in tumor cells, and whether this mechanism contributes to LJ12 antitumor activity.

The results of the present study are only 'proof-of-principle' and a substantial further investigation is required prior to LJ12 treatment being used in a clinical trials. In addition, the present study has certain limitations to be considered. Firstly, the present study only examined the effects of LJ12 in vitro, thus the in vivo toxicity of LJ12 is unknown. Secondly, the present study used a limited number of cell lines, and the majority of the investigations were confined to just one human cancer cell line. In addition, although the present study showed that LJ12 regulated the expression of certain proteins, how these mediate the antitumor activities of $\mathrm{LJ} 12$ remain to be elucidated. However, the preliminary data demonstrated the potential usefulness of LJ12 as an anticancer therapeutic agent. In addition, LJ12 demonstrates more marked antitumor activity and lower toxicity towards NSCLC cells in vitro, compared with the closely associated PPT derivative, VP16.

\section{Acknowledgements}

This study was supported, in part, by grants from the National Natural Science Foundation of China (grant nos. 81372177 and 21372110), the Medical Scientific Research Projects of Lanzhou Military Area Command of the Chinese People's Liberation Army (grant no. CLZ12JB04) and the Natural Science Foundation of Gansu Province (grant no. 1107RJZA106).

\section{References}

1. Torre LA, Bray F, Siegel RL, Ferlay J, Lortet-Tieulent J and Jemal A: Global cancer statistics, 2012. CA Cancer J Clin 65: 87-108, 2015.

2. Wood SL, Pernemalm M, Crosbie PA and Whetton AD: The role of the tumor-microenvironment in lung cancer-metastasis and its relationship to potential therapeutic targets. Cancer Treat Rev 40: 558-566, 2014.

3. Newman DJ, Cragg GM and Snader KM: Natural products as sources of new drugs over the period 1981-2002. J Nat Prod 7: 1022-1037, 2003.

4. Imbert TF: Discovery of podophyllotoxins. Biochimie 80: 207-222, 1998. 
5. Shen K, Sun L, Zhang H, Xu Y, Qian X, Lu Y, Li Q, Ni L and Liu J: A ROS-mediated lysosomal-mitochondrial pathway is induced by a novel Amonafide analogue, 7c, in human Hela cervix carcinoma cells. Cancer lett 333: 229-238, 2013.

6. Eberhardt WE, Gauler TC, Lepechoux C, Stamatis G, Bildat S, Krbek T, Welter S, Grunenwald D, Fischer B, Rodrigo Hde L, et al: 10-year long-term survival (LTS) of induction chemotherapy with three cycles cisplatin/paclitaxel followed by concurrent chemoradiation cisplatin/etoposide/45 Gy (1.5 Gy bid) plus surgery in locally advanced non-small-cell lung cancer (NSCLC)-a multicenter phase-II trial (CISTAXOL). Lung Cancer 82: 83-89, 2013.

7. Wood WA, Whitley J, Goyal R, Brown PM, Sharf A, Irons R, Rao KV, Essenmacher A, Serody JS, Coghill JM, et al Effectiveness of etoposide chemomobilization in lymphoma patients undergoing auto-SCT. Bone Marrow Transplant 48: 771-776, 2013.

8. Kumar A, Kumar V, Alegria AE and Malhotra SV: Synthetic and application perspectives of azapodophyllotoxins: Alternative scaffolds of podophyllotoxin. Curr Med Chem 18: 3853-3870, 2011.

9. Khaled M, Jiang ZZ and Zhang LY: Deoxypodophyllotoxin: A promising therapeutic agent from herbal medicine. J Ethnopharmacol 149: 24-34, 2013.

10. Jiang Z, Wu M, Miao J, Duan H, Zhang S, Chen M, Sun L, Wang Y, Zhang X, Zhu X and Zhang L: Deoxypodophyllotoxin exerts both anti-angiogenic and vascular disrupting effects. Int J Biochem Cell Biol 45: 1710-1719, 2013.

11. Carter GT: Natural products and Pharma 2011: Strategic changes spur new opportunities. Nat Prod Rep 28: 1783-1789, 2011

12. Jin Y, Liu J, Huang WT, Chen SW and Hui L: Synthesis and biological evaluation of derivatives of 4-deoxypodophyllotoxin as antitumor agents. Eur J Med Chem 46: 4056-4061, 2011.

13. Filloux F and Townsend JJ: Pre- and postsynaptic neurotoxic effects of dopamine demonstrated by intrastriatal injection. Exp neurol 119: 79-88, 1993

14. Vitale I, Galluzzi L, Castedo M and Kroemer G: Mitotic catastrophe: A mechanism for avoiding genomic instability. Nature Rev Mol Cell Biol 12: 385-392, 2011.

15. Shin SY, Bahk YY, Ko J, Chung IY, Lee YS, Downward J, Eibel H, Sharma PM, Olefsky JM, Kim YH, et al: Suppression of Egr-1 transcription through targeting of the serum response factor by oncogenic H-Ras. EMBO J 25: 1093-1103, 2006.
16. Bacso Z, Everson RB and Eliason JF: The DNA of annexin V-binding apoptotic cells is highly fragmented. Cancer Res 60: 4623-4628, 2000.

17. Roy RV, Suman S, Das TP, Luevano JE and Damodaran C: Withaferin A, a steroidal lactone from Withania somnifera, induces mitotic catastrophe and growth arrest in prostate cancer cells. J Nat Prod 76: 1909-1915, 2013.

18. Cotugno R, Fortunato R, Santoro A, Gallotta D, Braca A, De Tommasi $\mathrm{N}$ and Belisario MA: Effect of sesquiterpene lactone coronopilin on leukaemia cell population growth, cell type-specific induction of apoptosis and mitotic catastrophe. Cell Prolif 45: 53-65, 2012

19. Wang X, Wu E, Wu J, Wang TL, Hsieh HP and Liu X: An antimitotic and antivascular agent BPR0L075 overcomes multidrug resistance and induces mitotic catastrophe in paclitaxel-resistant ovarian cancer cells. PloS One 8: e65686, 2013.

20. Caruso R, Fedele F, Lucianò R, Branca G, Parisi C, Paparo D and Parisi A: Mitotic catastrophe in malignant epithelial tumors: The pathologist's viewpoint. Ultrastruct pathol 35: 66-71, 2011.

21. Vakifahmetoglu H, Olsson M and Zhivotovsky B: Death through a tragedy: Mitotic catastrophe. Cell Death Differ 15: 1153-1162, 2008.

22. Castedo M, Perfettini JL, Roumier T, Valent A, Raslova H, Yakushijin K, Horne D, Feunteun J, Lenoir G, Medema R, et al: Mitotic catastrophe constitutes a special case of apoptosis whose suppression entails aneuploidy. Oncogene 23: 4362-4370, 2004.

23. Jordan MA and Wilson L: Microtubules as a target for anticancer drugs. Nat Rev Cancer 4: 253-265, 2004.

24. Gerdes JM and Katsanis N: Microtubule transport defects in neurological and ciliary disease. Cell Mol Life Sci 62: 1556-1570, 2005.

25. Prinz H: Recent advances in the field of tubulin polymerization inhibitors. Expert Rev Anticancer Ther 2: 695-708, 2002.

26. Wei JH and Seemann J: Nakiterpiosin targets tubulin and triggers mitotic catastrophe in human cancer cells. Mol Cancer Ther 9: 3375-3385, 2010.

27. Jackson JR, Patrick DR, Dar MM and Huang PS: Targeted anti-mitotic therapies: Can we improve on tubulin agents? Nat Rev Cancer 7: 107-117, 2007

28. Cho RJ, Campbell MJ, Winzeler EA, Steinmetz L, Conway A, Wodicka L, Wolfsberg TG, Gabrielian AE, Landsman D, Lockhart DJ and Davis RW: A genome-wide transcriptional analysis of the mitotic cell cycle. Mol Cell 2: 65-73, 1998. 